\title{
Características fisiológicas e de crescimento de cafeeiro sombreado com guandu e cultivado a pleno sol(1)
}

\author{
Heverly Morais(2), Celso Jamil Marur(2), Paulo Henrique Caramori(2),
} Ana Maria de Arruda Ribeiro(3) e José Carlos Gomes ${ }^{(2)}$

\begin{abstract}
Resumo - O conhecimento dos efeitos do sombreamento sobre a fisiologia de cafeeiros é importante para se determinar níveis ótimos de radiação e temperatura, bem como para subsidiar estudos sobre o crescimento de plantas sombreadas, a fim de determinar a arquitetura ideal do cafeeiro que maximize a captura da radiação solar disponível em ambientes sombreados. O objetivo deste trabalho foi avaliar características fisiológicas e de crescimento de cafeeiros (Coffea arabica L.) cultivados sob sombreamento denso com guandu (Cajanus cajan (L.) Millsp.) e a pleno sol. O baixo nível de radiação incidente sobre os cafeeiros sombreados com guandu resultou em decréscimos na taxa fotossintética e na transpiração, maior altura de planta, folhas maiores e com menor quantidade de matéria seca. Esses resultados indicam que o excesso de sombra afeta drasticamente a fisiologia e morfologia de C. arabica.
\end{abstract}

Termos para indexação: Cajanus cajan, Coffea arabica, fotossíntese, transpiração, agrossilvicultura.

Physiological characteristics and growth of coffee plants grown under shade of pigeonpea and unshaded

\begin{abstract}
The characterization of shade effects on the physiology of coffee is important to determine optimum levels of radiation and temperature, as well as to subsidize studies on growth of shaded plants aiming at determining the ideal coffee plant architecture that maximizes the capture of the available solar radiation in shaded environments. The objective of this work was to evaluate physiological and growth characteristics of coffee (Coffea arabica L.) shaded with pigeonpea (Cajanus cajan (L.) Millsp.) and under full sun. The low level of incident radiation on the coffee shaded with pigeonpea caused decreases in the photosynthetic rate and transpiration, increased plant height and leaf size, but diminished leaf dry matter. These results indicate that the excess of shade drastically affects the physiology and morphology of C. arabica.
\end{abstract}

Index terms: Cajanus cajan, Coffea arabica, photosynthesis, transpiration, agroforestry.

\section{Introdução}

A utilização de sistemas agroflorestais na cafeicultura é uma técnica antiga e muito difundida na América Latina. No Brasil, embora haja predomínio

(1) Aceito para publicação em 18 de julho de 2003.

Extraído da dissertação de mestrado apresentada pela primeira autora à Universidade Estadual de Londrina (UEL), Londrina, PR.

(2) Instituto Agronômico do Paraná, Caixa Postal 481, CEP 86001-970 Londrina, PR. E-mail: heverly@eudoramail.com, cjmarur@iapar.br, caramori@iapar.br, jcgomes@iapar.br

(3) UEL, Centro de Ciências Agrárias, Dep. de Agronomia, Caixa Postal 6001, CEP 86051-990 Londrina, PR. E-mail: arruda@uel.br do cultivo a pleno sol, os cafeicultores estão, cada vez mais, aderindo ao sistema de cultivo sombreado, em razão da redução de custos de produção, aumento da renda do agricultor, melhoria da qualidade da bebida, preservação do ecossistema e melhoria das condições edafoclimáticas (Beer, 1987).

Adaptações de plantas da mesma espécie aos diferentes habitats estão associadas a características fisiológicas e morfológicas distintas (Larcher, 2000). Cafeeiros sombreados desenvolvem plantas mais altas, suas folhas são maiores e mais finas, permitindo uma melhor captação da energia solar disponível (Fahl et al., 1994). Os níveis de radiação e temperatura sobre os cafeeiros, bem como a água e nutrientes disponíveis para a planta, são fatores importantes na regulação da atividade fotossintética. Segundo Kumar \& Tieszen (1980), cafeeiros sob moderada 
irradiância (entre 1.200 e $1.300 \mu \mathrm{mol} \mathrm{m}{ }^{-2} \mathrm{~s}^{-1}$ ) não sofreram perdas na atividade fotossintética. No entanto, radiações acima de $2.200 \mu \mathrm{mol} \mathrm{m}{ }^{-2} \mathrm{~s}^{-1}$, comuns em dias ensolarados nas regiões tropicais, podem induzir a fotoinibição (Nunes et al., 1993). Reduções na assimilação de $\mathrm{CO}_{2}$ observadas em folhas de cafeeiros sob alta radiação têm sido associadas com temperaturas foliares entre $25^{\circ} \mathrm{C}$ e $35^{\circ} \mathrm{C}$, as quais provocam decréscimo na condutância do mesofilo (Kumar \& Tieszen, 1980). A elevada radiação não diminuiu a fotossíntese em folhas de cafeeiros quando a temperatura na câmara de assimilação de $\mathrm{CO}_{2}$ foi mantida até $25^{\circ} \mathrm{C}$ (Fahl et al., 1994). Por outro lado, Kumar \& Tieszen (1980) observaram que a fotossíntese em plantas sombreadas foi substancialmente maior que naquelas a pleno sol, com a temperatura foliar em torno de $25^{\circ} \mathrm{C}$.

O sombreamento natural é um dos fatores mais importantes na interceptação da radiação, pois a densidade e a arquitetura da copa da espécie de porte mais alto determinam a fração de energia solar que pode ser captada pelas plantas subjacentes (Monteith, 1965). Assim, o conhecimento dos efeitos do sombreamento sobre a fisiologia de cafeeiros é importante para se determinar níveis ótimos de radiação e temperatura, já que nesses aspectos residem as causas de diferentes atividades fotossintéticas. Estudos sobre o crescimento de plantas sombreadas dão suporte à busca da arquitetura ideal de cafeeiro, que maximize a captação da radiação solar disponível em ambientes sombreados. Assim, as respostas fisiológicas e de crescimento de cafeeiros irão determinar a melhor combinação dos elementos de manejo de sombras em sistemas agroflorestais, resultando em aumentos na produtividade (Cannell, 1975; Baggio et al., 1997).

O objetivo deste trabalho foi avaliar características fisiológicas e de crescimento em cafeeiros sombreados com guandu (Cajanus cajan), comparativamente àqueles cultivados a pleno sol.

\section{Material e Métodos}

O experimento foi realizado no campo na área experimental do IAPAR em Londrina, PR, cujas coordenadas geográficas são: latitude $23^{\circ} 23^{\prime} \mathrm{S}$ e longitude $50^{\circ} 11^{\prime} \mathrm{W}$, e a altitude $610 \mathrm{~m}$. O solo é do tipo Latossolo
Roxo distroférrico, com 82\% de argila. O clima da região é do tipo Cfa, segundo a classificação de Köppen, isto é, trata-se de clima subtropical úmido, com verão quente. A temperatura média anual é de $21^{\circ} \mathrm{C}$, sendo a média do mês mais quente (janeiro) de $24^{\circ} \mathrm{C}$ e a média do mês mais frio (junho) $17^{\circ} \mathrm{C}$. A precipitação média anual é de $1.630 \mathrm{~mm}$; os meses mais chuvosos são dezembro, janeiro e fevereiro e os meses mais secos são junho, julho e agosto (Caviglione et al., 2000).

Foram avaliados, de dezembro/2000 a agosto/2002, cafeeiros da espécie Coffea arabica da cultivar IPR 99, plantados em 10/12/1998, em um espaçamento de $2,5 \times 0,70 \mathrm{~m}$ com uma planta por cova e recepados a $30 \mathrm{~cm}$ de altura em setembro de 2000. A área experimental total foi de $6.000 \mathrm{~m}^{2}$, dividida em duas subáreas contendo cafeeiros cultivados a pleno sol e cafeeiros em plantio intercalado com guandu comum (Cajanus cajan), linhagem IAPAR PPP-832. O mesmo foi semeado nas entre linhas dos cafeeiros na densidade de três plantas $/ \mathrm{m}$, em dezembro de 2000, atingindo em maio de 2001 seu crescimento vegetativo máximo (4 $\mathrm{m}$ de altura) e cobrindo totalmente os cafeeiros. Em setembro de 2001 o guandu foi podado a $60 \mathrm{~cm}$ de altura, retomou o crescimento e atingiu novamente sua altura máxima (cerca de $4 \mathrm{~m}$ ) em abril de 2002. A densidade de sombreamento foi caracterizada por meio de medição da radiação solar global incidente sobre as copas dos cafeeiros sombreados e a pleno sol, utilizando piranômetros LI-COR (modelo LI200X) acoplados a um micrologger. A redução na radiação solar global incidente sobre as copas dos cafeeiros pelo dossel de guandu propiciou um ambiente típico de sombra, em que a porcentagem de interceptação da radiação solar global variou de $17 \%$ a $88 \%$ durante o período experimental (Figura 1).

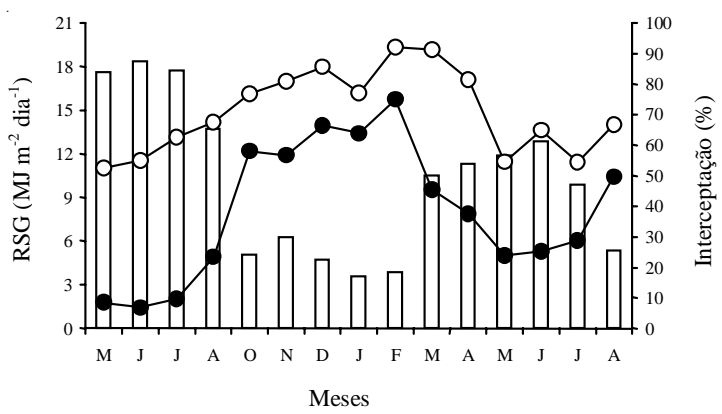

Figura 1. Distribuição mensal da Radiação Solar Global (RSG) entre maio de 2001 e agosto de 2002, em cafeeiros sombreados (๑) e cafeeiros a pleno sol (O). As colunas correspondem à porcentagem de interceptação das radiações pelo guandu. 
As caracterizações fisiológicas foram realizadas em três plantas de cada tratamento, escolhidas ao acaso. As avaliações ocorreram sob três condições de densidade de sombreamento: cafeeiros totalmente sombreados com guandu (C1), realizada no dia 22/8/2001; cafeeiros sem cobertura, um dia após a poda do guandu (C2), realizada no dia 5/9/2001 e cafeeiros parcialmente cobertos, após a rebrota do guandu (C3), realizada dia 24/10/2001. As medições foram efetuadas no período das 7 às 18 horas, excetuando a primeira avaliação (C1) que ocorreu das 8 às 15 horas. Foram selecionadas folhas correspondentes ao 2o par de folhas do ramo plagiotrópico a contar do ápice, plenamente expostas à luz solar e orientadas no sentido leste/oeste em relação à luz solar incidente, com estrutura fisiológica definida e máxima atividade metabólica.

Em duas folhas de cada planta, procedeu-se à avaliação de fotossíntese líquida e transpiração por meio de um sistema portátil de fotossíntese (LI-COR, modelo LI-6200 e analisador de gás LI-6250). As informações fornecidas pelo sistema foram processadas conforme Marur \& Vieira (1997) e os dados de fotossíntese líquida ajustados a uma regressão polinomial assimétrica, de acordo com Pereira \& Arruda (1987). A comparação das linhas de regressão ajustadas para cada tratamento foi feita por meio do teste F, a $5 \%$ de probabilidade, conforme Neter \& Wasserman (1974).

As medições das características de crescimento foram feitas em dez plantas, em abril/2001, setembro/2001, março/ 2002 e agosto/2002 e as variáveis foram altura de planta, número de ramos plagiotrópicos e diâmetro de copa. Foi introduzida uma haste de madeira ao lado do tronco de cada cafeeiro avaliado, a qual serviu como ponto inicial das medições de altura para se evitar variações dos desníveis da superfície. As medidas de diâmetro da copa foram feitas na altura do primeiro par de ramos inferior. Os dados foram submetidos à comparação de médias pelo teste t de Student.

O crescimento foliar foi avaliado em outras dez plantas de cada tratamento, escolhidas ao acaso. Para tanto, foram coletadas quatro folhas de cada planta, correspondentes ao $2^{\circ}$ par de folhas do ramo plagiotrópico a contar do ápice. Escolheram-se folhas posicionadas no limite superior e inferior da planta e voltadas para as faces norte e sul. As variáveis avaliadas foram área foliar, massa de matéria verde, massa de matéria seca, e massa foliar específica. A área foliar foi medida com o instrumento LI-3000 (LICOR). Na obtenção da matéria seca, as amostras permaneceram durante cinco dias em uma estufa com temperatura em torno de $55^{\circ} \mathrm{C}$. A massa foliar específica foi determinada pela razão entre a massa de matéria seca e a área foliar. Os dados foram submetidos à comparação de médias pelo teste $t$ de Student.

\section{Resultados e Discussão}

A fotossíntese líquida, nas três condições avaliadas, apresentou valores significativamente menores em cafeeiros sombreados (Figura 2). As diferenças devem-se às particularidades anatômicas das folhas e características metabólicas.
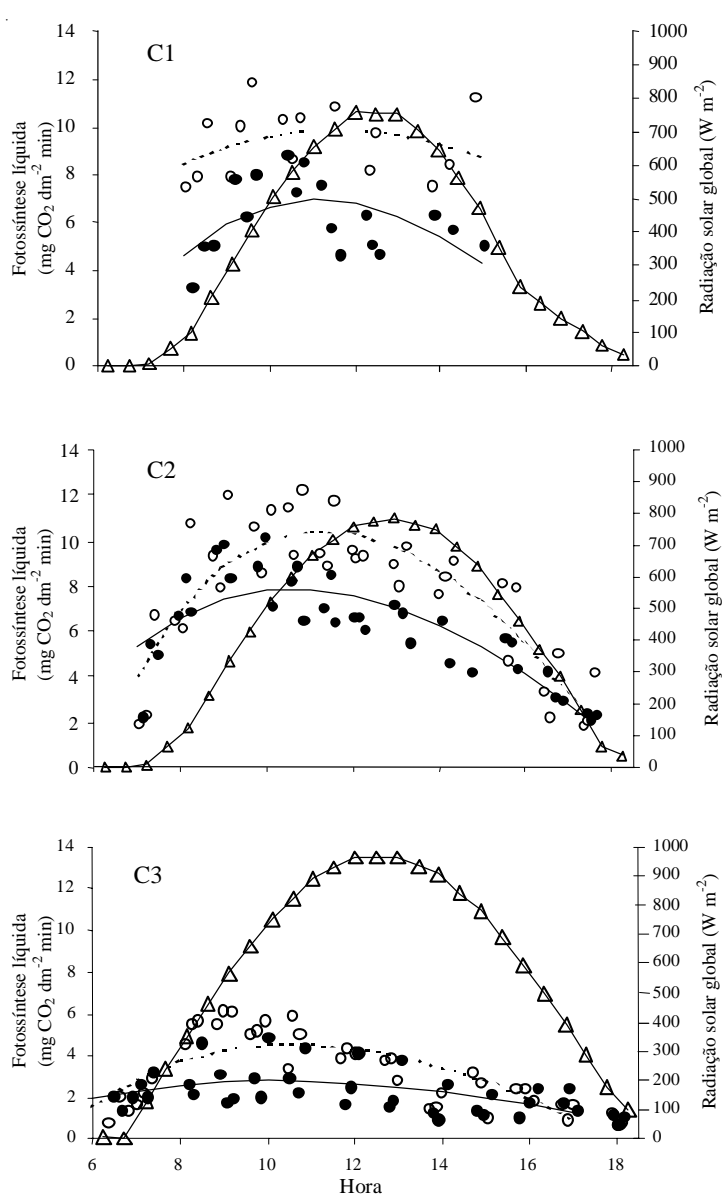

Figura 2. Fotossíntese líquida medida no decorrer do dia em cafeeiros sombreados com guandu (•) em seu melhor ajuste (linha cheia) e cafeeiros a pleno sol (o) em seu melhor ajuste (linha interrompida) e radiação solar global incidente sobre os cafeeiros cultivados a pleno sol $(\Delta)$, em cafeeiros totalmente sombreados com guandu (C1), em cafeeiros sem cobertura, um dia após a poda do guandu (C2) e em cafeeiros parcialmente cobertos, 50 dias após a poda do guandu (C3). 
O denso sombreamento sobre os cafeeiros durante a maior parte do período experimental reduziu drasticamente a radiação fotossintética incidente, provocando redução no número de estômatos, na espessura do mesofilo e aumento dos espaços intercelulares (Voltan et al., 1992; Morais, 2003). Tais características estão estreita e negativamente relacionadas ao processo de fotossíntese.

Em C2 (Figura 2), nota-se que, apesar de ambos tratamentos estarem sob as mesmas condições de radiação, os cafeeiros anteriormente sombreados continuaram apresentando menores taxas fotossintéticas. Isso ocorreu porque as folhas se adaptam de forma modificativa e definem suas estruturas internas de acordo com as condições médias de radiação, preponderantemente durante a morfogênese, e esta diferenciação fenotípica de tecidos geralmente não é reversível (Larcher, 2000). As maiores taxas fotossintéticas nos cafeeiros cultivados a pleno sol ocorreram no período da manhã. As plantas têm decréscimos rápidos de fotossíntese sob intensa radiação solar e temperatura elevada, principalmente em decorrência do fechamento dos estômatos, sendo que no período da manhã é que se encontram as condições ótimas e a taxa máxima de fotossíntese (Nutman, 1937).

As maiores taxas fotossintéticas verificadas em C1 e C2, comparativamente a C3 (Figura 2), ocorreram em virtude da fase de desenvolvimento e suprimento hídrico das plantas. Segundo Larcher (2000), há aumento da capacidade fotossintética durante a floração e a frutificação de plantas cultivadas, fases em que se encontravam as plantas nas respectivas avaliações. Quando os frutos são removidos, fase de desenvolvimento verificada em C3, a capacidade fotossintética diminui.

No período da avaliação C3, houve também pouca disponibilidade de água, pois a precipitação do mês de outubro foi de apenas 48,9 mm, enquanto a média histórica para este mês é de 130 mm. Embora a água seja, além do $\mathrm{CO}_{2}$, necessária para a fotossíntese, sua grande importância está na manutenção da hidratação do protoplasma. Com o déficit hídrico, a atividade fotossintética declina paralelamente à diminuição do volume celular e, portanto, concomitantemente ao declínio da turgescência (Sutcliffe, 1980).
Experiências realizadas na Costa Rica (Cannell, 1975) e no Brasil (Fahl et al., 1994; Carelli et al., 1999) demonstraram que a fotossíntese é menor em cafeeiros cultivados em condições sombreadas, quando comparada a cafeeiros cultivados a pleno sol. Nutman (1937) e Kumar \& Tieszen (1980) encontraram menor atividade fotossintética em cafeeiros expostos à plena luz solar. Convém salientar que quando se compara essa variável entre trabalhos realizados, devemse considerar alguns fatores que afetam os processos fisiológicos dos cafeeiros, tais como condições do clima (temperatura e radiação), condições do experimento (vaso ou campo), idade da planta, genótipo e sua adaptabilidade ao clima local, tipo de sombreamento (natural ou artificial), espécie utilizada e densidade de sombreamento (Carelli et al., 1999).

Nos cafeeiros a pleno sol, as temperaturas de folha foram mais elevadas em virtude da exposição a intensa radiação solar (Figura 3); conseqüentemente, intensificou-se a diferença de pressão de vapor entre o ar e a folha, resultando em taxas mais elevadas de transpiração, que cumprem, ao final, o papel termo-regulador (Sutcliffe, 1980). Por sua vez, as folhas das plantas sob sombreamento apresentaram temperaturas mais amenas e, conseqüentemente, menores transpirações.

Na condição C3 (Figura 3), os valores de transpiração foliar, em ambos os tratamentos, diminuíram consideravelmente em relação às condições C1 e C2, enquanto os valores de temperatura elevaram-se. A diminuição da transpiração ocorreu em decorrência do pouco suprimento hídrico verificado no mês de outubro. Quando o solo se encontra com baixa disponibilidade de água, a evapotranspiração é restringida e a maior parte da energia disponível é utilizada para aquecimento do ar, da planta e do solo (Pereira et al., 2002). Comparando os tratamentos, especialmente na condição C3, observa-se que tanto a transpiração quanto a temperatura foliar foram ainda menores nos cafeeiros sombreados. Isso mostra os efeitos benéficos da arborização, em condições de estresse, ao reduzir perdas de água e diminuir o aquecimento da planta. Nutman (1941) verificou que a transpiração do cafeeiro aumentou proporcionalmente com a intensidade luminosa até certo nível e reduziu sob altas intensidades luminosas, provavelmente em ra- 
zão do fechamento parcial ou temporário dos estômatos.

O sombreamento induziu maior crescimento em altura (Tabela 1), evidenciado a partir da terceira avaliação. Esse crescimento acentuado é um mecanismo denominado estiolamento, que otimiza a captação de luz. Fahl et al. (1994) e Carelli et al. (1999)


Figura 3. Transpiração foliar medida no decorrer do dia em cafeeiros sombreados com guandu $(\boldsymbol{\bullet})$ e cafeeiros a pleno sol (O) e temperatura da folha nos cafeeiros cultivados a pleno sol (linha interrompida) e nos cafeeiros sombreados (linha cheia); em cafeeiros totalmente sombreados (C1), em cafeeiros sem cobertura, um dia após a poda do guandu (C2) e em cafeeiros parcialmente cobertos, 50 dias após a poda do guandu (C3). observaram que o sombreamento excessivo reduziu o crescimento de Coffea arabica. Suárez de Castro et al. (1961), analisando plantas jovens em condições de viveiro, observaram maior crescimento em altura nos ambientes com maior densidade de sombra.

Com relação ao número de ramos, os cafeeiros cultivados a pleno sol apresentaram maior número de ramos, notadamente na segunda avaliação (Tabela 1). Segundo Larcher (2000), as plantas que crescem sob forte radiação desenvolvem um vigoroso sistema de ramos. Resultados semelhantes foram obtidos por Suárez de Castro et al. (1961).

O sombreamento provocou aumento no tamanho individual das folhas dos cafeeiros, mas resultou em folhas com menor massa de matéria seca e menor massa específica (Tabela 2), o que proporciona maior e melhor interceptação da energia disponível no sistema. Por sua vez, plantas cultivadas a pleno sol desenvolveram folhas menores, mais densas (Tabela 2) com grande espessura da parede celular, cutícula e mesofilo (Morais, 2003), caracterizando o desenvolvimento de reforços mecânicos para evitar

Tabela 1. Caracterização do crescimento de plantas de Coffea arabica cultivadas em sombreamento de guandu e a pleno sol, em quatro épocas de avaliação.

\begin{tabular}{lcccr}
\hline \multicolumn{1}{c}{$\begin{array}{c}\text { Época de } \\
\text { avaliação }\end{array}$} & $\begin{array}{c}\text { Cafeeiro } \\
\text { sombreado }\end{array}$ & $\begin{array}{c}\text { Cafeeiro a } \\
\text { pleno sol }\end{array}$ & Valor de t & Pr $>|\mathrm{t}|$ \\
\hline \multicolumn{5}{c}{ Altura $(\mathrm{cm})$} \\
Abril/2001 & 51,00 & 51,5 & $0,13^{\mathrm{ns}}$ & 0,8964 \\
Setembro/2001 & 63,20 & 64,8 & $-0,51^{\mathrm{ns}}$ & 0,6182 \\
Março/2002 & 107,40 & 94,3 & $4,39^{* *}$ & 0,0002 \\
Agosto/2002 & 120,47 & 104,5 & $4,19^{* *}$ & 0,0003 \\
\hline \multicolumn{5}{c}{ Número de ramos } \\
Abril/2001 & 14,00 & 15,2 & $-0,89^{\mathrm{ns}}$ & 0,3815 \\
Setembro/2001 & 18,13 & 24,8 & $4,84^{* *}$ & $<0,0001$ \\
Março/2002 & 36,53 & 40,0 & $-1,90^{\mathrm{ns}}$ & 0,0696 \\
Agosto/2002 & 42,80 & 46,0 & $-1,85^{\mathrm{ns}}$ & 0,0777 \\
\hline \multicolumn{5}{c}{}
\end{tabular}

Tabela 2. Área e massa de folhas de plantas de Coffea arabica cultivadas sob sombreamento de guandu e a pleno sol.

\begin{tabular}{lcccc}
\hline $\begin{array}{l}\text { Características de } \\
\text { crescimento }\end{array}$ & $\begin{array}{c}\text { Cafeeiro } \\
\text { sombreado }\end{array}$ & $\begin{array}{c}\text { Cafeeiro a } \\
\text { pleno sol }\end{array}$ & & Valor de $\mathrm{Pr}>|\mathrm{t}|$ \\
\hline Área foliar $\left(\mathrm{cm}^{2}\right)$ & 64,53 & 49,63 & $-7,47^{* *}$ & $<0,0001$ \\
Massa de matéria verde (g) & 1,50 & 1,54 & $0,93^{\mathrm{ns}}$ & 0,3566 \\
Massa de matéria seca (g) & 0,53 & 0,59 & $2,76^{* *}$ & 0,0086 \\
Massa específica $\left(\mathrm{g} \mathrm{cm}{ }^{-2}\right)$ & 0,008338 & 0,011935 & $13,26^{* *}$ & $<0,0001$ \\
\hline nsNão-significativo. ${ }^{* *}$ Significativo a $1 \%$ de probabilidade.
\end{tabular}

Pesq. agropec. bras., Brasília, v. 38, n. 10, p. 1131-1137, out. 2003 
perda de água. Carelli et al. (1999) estudando mudas de $C$. arabica sob cobertura artificial, observaram redução da área foliar total sob denso sombreamento (80\% de sombra).

As características de desenvolvimento foliar variaram de acordo com a posição da folha na planta (Tabela 3). Folhas da parte superior e orientadas para o norte não apresentaram diferenças significativas entre os tratamentos na maioria das variáveis (área foliar, massa de matéria verde e massa de matéria seca), ou seja, as folhas presentes nesta posição da planta nos cafeeiros sombreados tendem a ter morfologia similar às folhas de plantas cultivadas a pleno sol (menores e compactas), pois estão mais expostas à radiação solar. As folhas podem variar em forma, tamanho, espessura, densidade e rusticidade, considerando diferentes posicionamentos numa mesma planta, porque estão expostas a condições microclimáticas diversas, provocando alterações hormonais e, por conseguinte, modificações estruturais e morfológicas (Medri \& Perez, 1980). Esse efeito é conhecido como auto-sombreamento. Assim, folhas mais expostas à radiação podem ser morfologicamente diferentes das folhas menos expostas de uma mesma planta. Comparando folhas

Tabela 3. Caracterização da área e massa de folhas situadas em diferentes locais da planta de Coffea arabica cultivada sob sombreamento de guandu e a pleno sol.

\begin{tabular}{|c|c|c|c|c|c|}
\hline $\begin{array}{l}\text { Face } \\
\text { exposta }\end{array}$ & $\begin{array}{c}\text { Região } \\
\text { da planta }\end{array}$ & $\begin{array}{c}\text { Cafeeiro } \\
\text { sombreado }\end{array}$ & $\begin{array}{c}\text { Cafeeiro a } \\
\text { pleno sol }\end{array}$ & Valor de $\mathrm{t}$ & $\operatorname{Pr}>|t|$ \\
\hline & & \multicolumn{4}{|c|}{ Área foliar $\left(\mathrm{cm}^{2}\right)$} \\
\hline \multirow[t]{2}{*}{ Norte } & Superior & 59,138 & 48,941 & $-24,5400^{\mathrm{ns}}$ & 0,05140 \\
\hline & Inferior & 77,352 & 51,006 & $-6,4099 * *$ & 0,00012 \\
\hline \multirow[t]{2}{*}{ Sul } & Superior & 55,567 & 44,607 & $-5,9090 *$ & 0,02270 \\
\hline & Inferior & 66,052 & 53,969 & $-4,1967 * *$ & 0,00232 \\
\hline & & \multicolumn{4}{|c|}{ Massa de matéria verde (g) } \\
\hline \multirow[t]{2}{*}{ Norte } & Superior & 1,383 & 1,57500 & $1,6300^{\mathrm{ns}}$ & $-0,13750$ \\
\hline & Inferior & 1,783 & 1,62600 & $-1,2474^{\mathrm{ns}}$ & 0,24372 \\
\hline \multirow[t]{2}{*}{ Sul } & Superior & 1,352 & 1,40600 & $1,0085^{\mathrm{ns}}$ & 0,33956 \\
\hline & Inferior & 1,471 & 1,55670 & $1,8199^{\mathrm{ns}}$ & 0,10212 \\
\hline \multirow{3}{*}{ Norte } & & \multicolumn{4}{|c|}{ Massa de matéria seca (g) } \\
\hline & Superior & 0,515 & 0,597 & $1,79433^{\text {ns }}$ & 0,10634 \\
\hline & Inferior & 0,615 & 0,627 & $0,22399^{\text {ns }}$ & 0,82626 \\
\hline \multirow[t]{2}{*}{ Sul } & Superior & 0,494 & 0,532 & $1,57245^{\mathrm{ns}}$ & 0,15030 \\
\hline & Inferior & 0,515 & 0,597 & $3,33041 * *$ & 0,00879 \\
\hline \multirow{3}{*}{ Norte } & & \multicolumn{4}{|c|}{ Massa específica $\left(\mathrm{g} \mathrm{cm}^{-2}\right)$} \\
\hline & Superior & 0,008717 & 0,12478 & $4,14333^{* *}$ & 0,0025 \\
\hline & Inferior & 0,007949 & 0,12248 & $12,32665 * *$ & $<0,0001$ \\
\hline \multirow[t]{2}{*}{ Sul } & Superior & 0,888300 & 0,01195 & $9,85717^{* *}$ & $<0,0001$ \\
\hline & Inferior & 0,007802 & 0,01106 & $9,03073^{* *}$ & $<0,0001$ \\
\hline
\end{tabular}

ns Não-significativo. * e **Significativo a $5 \%$ e a $1 \%$ de probabilidade respectivamente situadas nas porções superior e inferior da planta, observa-se que, independentemente do tratamento e face exposta, todas as variáveis apresentaram maiores valores na região inferior (Tabela 3). Segundo Dickison (2000), as folhas de sol são menores, mais espessas e mais rústicas em relação às folhas de sombra de uma mesma copa, por terem maior quantidade de tecidos protetores. A rusticidade é dada pela forte compactação mesofílica, com abundante parênquima paliçádico em relação ao lacunoso, muitos tecidos mecânicos como colênquima e esclerênquima, além de grande espessamento cuticular (Medri \& Perez, 1980).

\section{Conclusão}

Os cafeeiros sob sombreamento denso de guandu, comparados a cafeeiros cultivados a pleno sol, apresentam menores taxas de transpiração e fotossíntese, maior crescimento em altura, menor número de ramos plagiotrópicos e folhas maiores com menor acúmulo de matéria seca.

\section{Referências}

BAGGIO, A. J.; CARAMORI, P. H.; ANDROCIOLI FILHO, A.; MONTOYA, L. Productivity of southern Brazilian coffee plantations shaded by different stockings of Grevillea robusta. Agroforestry Systems, Amsterdam, v. 37, n. 2, p. 111-120, 1997.

BEER, J. W. Advantages, disadvantages and desirable characteristics of shade trees for coffee, cacao and tea. Agroforestry Systems, Amsterdam, v. 5, p. 3-13, 1987.

CANNELL, M. G. R. Crop physiological aspects of coffee bean yield: a review. Journal of Coffee Research, Karnataka, v. 5, n. 1/2, p. 7-20, 1975.

CARELLI, M. L. C.; FAHL, J. I.; TRIVELIN, P. C. O.; QUEIROZ-VOLTAN, R. B. Carbon isotope discrimination and gas exchange in Coffea species grown under different irradiance regimes. Revista Brasileira de Fisiologia Vegetal, Brasília, v. 11, n. 2, p. 63-68, 1999.

CAVIGLIONE, J. H.; CARAMORI, P. H.; KIIHL, L. B.; OLIVEIRA, D. Cartas climáticas do Paraná. Londrina: Iapar, 2000. 1 CD-ROM.

DICKISON, W. C. Integrative plant anatomy. New York: Harcourt/Academic, 2000. 533 p. 
FAHL, J. I.; CARELLI, M. L. C.; VEGA, J.; MAGALHÃES, A. C. Nitrogen and irradiance levels affecting net photosynthesis and growth of young coffee plants (Coffea arabica L.). Journal of Horticultural Science, Ashford, v. 69, p. 161-169, 1994.

KUMAR, D.; TIESZEN, L. L. Photosynthesis in Coffea arabica: effects of light and temperature. Experimental Agriculture, New York, v. 16, n. 1, p. 13-19, 1980.

LARCHER, W. Ecofisiologia vegetal. São Carlos: Rima, 2000. $531 \mathrm{p}$.

MARUR, C. J.; VIEIRA, L. G. E. Spreadsheet macros for handling data collected from the LI-6200 portable photosynthesis system. Revista Brasileira de Agrometeorologia, Santa Maria, v. 5, n. 1, p. 133-135, 1997.

MEDRI, M. E.; PEREZ, E. L. Aspectos da anatomia ecológica de folhas de Hevea brasiliensis Mell. Arg. Acta Amazonica, Manaus, v. 10, n. 3, p. 463-493, 1980.

MONTEITH, J. L. Light distribution and photosynthesis in field crops. Annals of Botany, London, v. 29, n. 113, p. 17-37, 1965.

MORAIS, H. Efeitos do sombreamento de cafeeiros (Coffea Arabica L.) com guandu (Cajanus Cajan (L.) Millsp.) no norte do Paraná. 2003. 118 f. Dissertação (Mestrado em Agrometeorologia) - Universidade Estadual de Londrina, Londrina, 2003.

NETER, J.; WASSERMAN, W. Applied linear statistical models: regression, analysis of variance and experimental designs. Chicago: Richard D. Irwin, 1974. 842 p.
NUNES, M. A.; RAMALHO, J. D. C.; DIAS, M. A. Effects of light and photosynthetic performance of leaves from coffee plants exposed to bright light. Journal of Experimental Botany, London, v. 44, n. 262, p. 893-899, 1993.

NUTMAN, F. J. Photosynthesis of coffee leaves under natural conditions. Annals of Botany, London, v. 1, n. 3, p. 353-367, 1937.

NUTMAN, F. J. Studies of the physiology of Coffea arabica - III: respiration rates of whole trees in relation to natural environmental conditions. Annals of Botany, London, v. 5, n. 17, p. 59-81, 1941.

PEREIRA, A. R.; ARRUDA, H. V. Ajuste prático de curvas na pesquisa biológica. Campinas: Fundação Cargill, 1987.50 p.

PEREIRA, A. R.; ANGELOCCI, L. R.; SENTELHAS, P. C. Agrometeorologia: fundamentos e aplicações práticas. Guaíba: Agropecuária, 2002. 478 p.

SUÁREZ DE CASTRO, F.; MONTENEGRO, L.; AVILES, P. C.; MORENO, M.; BOLAÑOS, M. Efecto del sombrío en los primeros años de vida de un cafetal. Café, Turrialba, v. 3, n. 10, p. 81-102, 1961.

SUTCLIFFE, J. F. As plantas e a água. São Paulo: Edusp, 1980. $67 \mathrm{p}$.

VOLTAN, R. B. Q.; FAHL, J. I.; CARELLI, M. L. C. Variações na anatomia foliar de cafeeiros submetidos a diferentes intensidades luminosas. Revista Brasileira de Fisiologia, Brasília, v. 4, n. 2, p. 99-105, 1992. 